NASA-TM-81193 19800015493

\title{
Clarification Process: Resolution of Decision-Problem Conditions
}

\section{Duncan L. Dieterly}

May 1980

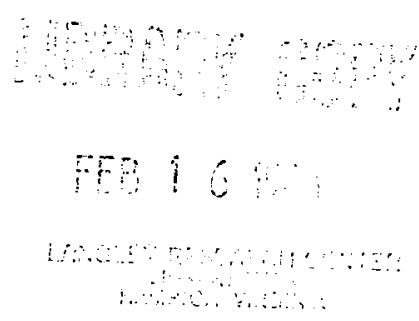


31176013227898 


\section{Clarification Process: Resolution of Decision-Problem Conditions}

Duncan L. Dieterly, Air Force Human Resources Laboratory Technology Office Ames Research Center, Moffett Field, California

\section{NRSก}

National Aeronautics and

Space Administration

AFHRL

Ames Research Center

Moffett Field, California 94035

Technology

Office 
TABLE OF CONTENTS

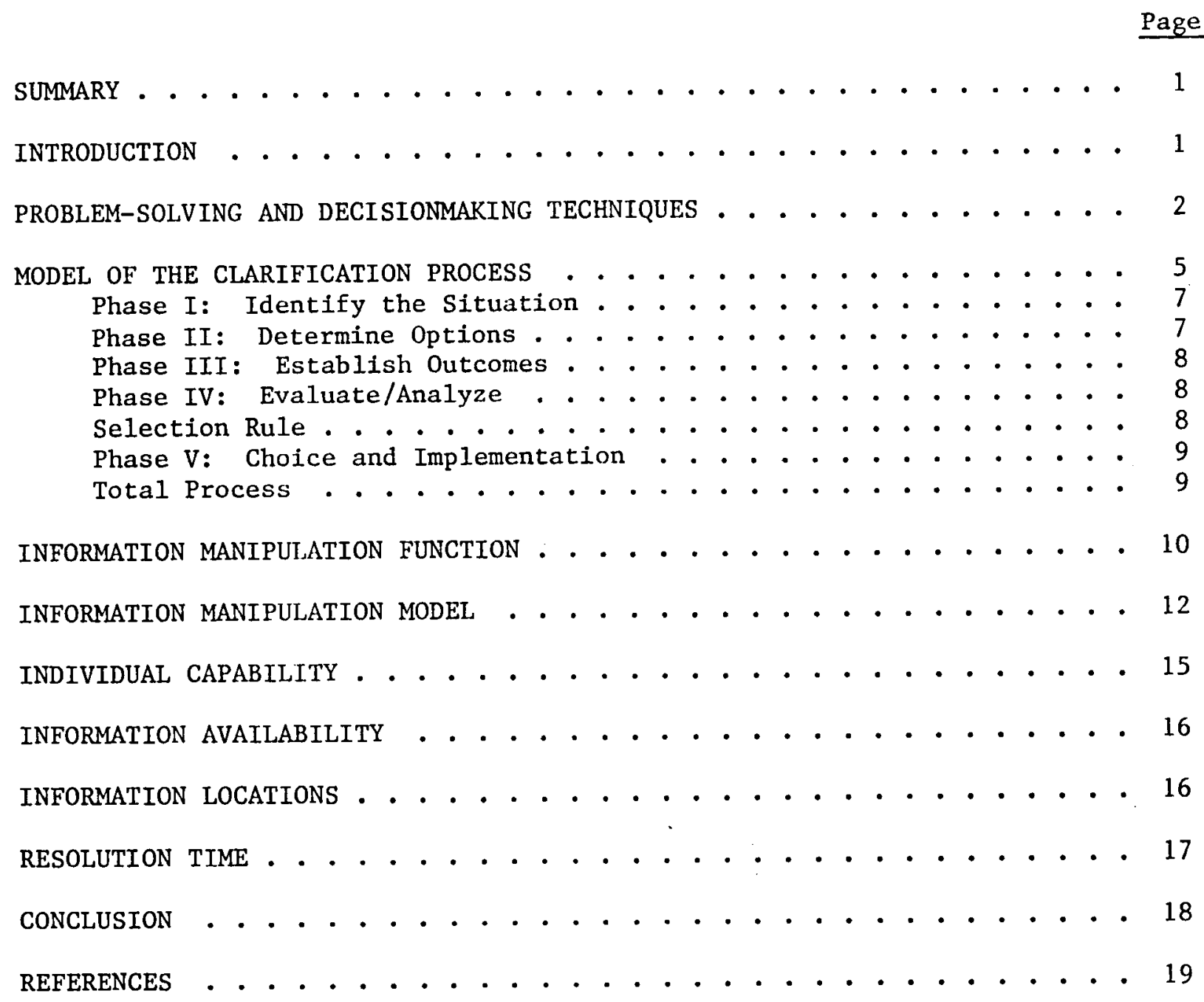


Figure 1.- Clarification process model. . . . . . . . . . . . 6

Figure 2.- Information manipulation model . . . . . . . . . . . 10

Figure 3.- Information manipulation: stage 1 . . . . . . . . . . 13

Figure 4.- Information manipulation: stage 2 . . . . . . . . . . 14

Figure 5.- Information manipulation: stage 3 . . . . . . . . . . 15

LIST OF TABLES

TABLE 1.- REPRESENTATIVE APPROACHES TO PROBLEM SOLVING . . . . . . . . . 3

TABLE 2.- REPRESENTATIVE APPROACHES TO DECISIONMAKING . . . . . . . . . 4 


\title{
CLARIFICATION PROCESS: RESOLUTION OF DECISION-PROBLEM CONDITIONS
}

\author{
Duncan L. Dieterly \\ Ames Research Center and \\ Air Force Human Research Laboratory Technology Office
}

SUMMARY

In this paper, the process that is applied to resolving a problem or making a decision will be called the clarification process. The process will be presented in terms of two models linked together to provide a single approach to accommodate the behavior of interest. The objective, therefore, is to postulate a model which adequately explains the process in terms of current knowledge. The model will establish a capability to (1) explain decisionmaking and problem-solving behavior, (2) demonstrate how to make decisions and solve problems, and (3) analyze the causes of failure to solve a problem or make a decision. The clarification process model will further structure an unclear aspect of these two concepts.

The clarification model is a model of a general process which occurs in both decisionmaking and problem-solving tasks. The model is highly dependent on information flow. The model addresses the possible constraints of individual indifferences and experience in achieving success in resolving decisionproblem conditions. As indicated, the application of the clarification process model is only necessary for certain classes of the basic decisionproblem condition. With less complex decision-problem conditions, certain phases of the model may be omitted. The model may be applied across a wide range of decision-problem conditions.

The model consists of two major components. The five-phase prescriptive sequence based on previous approaches to both concepts and the information manipulation function which draws upon current ideas in the areas of information processing, computer programming, memory, and thinking. The two components are linked together to provide a structure that assists in understanding the process of resolving problems and making decisions. Current research in both areas has been directed along different paths. However, it is appropriate to bring it back to the critical issue of how to resolve problems and make decisions. The process as modeled in this paper establishes the critical link between the two concepts.

\section{INTRODUCTION}

In this paper, the process that is applied to resolving a problem or making a decision will be called the clarification process. The process will be presented in terms of two models linked together to provide a single approach to accommodate the behavior of interest. The objective, therefore, is to postulate a model that adequately explains the process in terms of current knowledge. The model will establish a capability to (1) explain 
decisionmaking and problem-solving behavior, (2) demonstrate how to make decisions and solve problems, and (3) analyze the causes of failure to solve a problem or to make a decision. The clarification process model will further structure an unclear aspect of these two concepts.

This report represents the work accomplished by the AFHRL Technology office, Ames Research Center, NASA. The effort was accomplished in support of a NASA project in the area of resource management. The material presented was developed by the AFHRL Technology office and provided to the Man-Vehicle Systems Research Division of the Life Sciences Directorate as a possible source of input to later stages of its project.

\section{Problem-Solving and Decisionmaking Techniques}

Explanations of the decisionmaking and problem-solving processes are fairly abundant. These may be called techniques or methods for solving problems or making decisions. They are prescriptive in nature and heavily indebted to the field of logic. They are based on the logical analyses of the decision-problem condition and provide a sequence of appropriate steps to follow. If these approaches are analyzed, they have a consistent set of properties. In reviewing these models, a set of sequential tasks that culminate in a decision or solution, if accomplished, can be distinguished. The number of these tasks varies from three to nine, but the general agreement across approaches is striking. Even in comparing problem-solving and decisionmaking methods, the similarities far outweigh the differences. Tables 1 and 2 show some characteristic examples of approaches to problem solving and decisionmaking.

The approaches to problem solving are based on the research generated in the areas of learning and thinking. As can be seen in Wallas' (1926) work, the basic approach was to analyze the process in terms of a single task. The concept of incubation was also historically predominant in earlier years. The concept implies a period of unconscious or at least unplanned activity that yields some kind of advance in the solution. The approaches are influenced by two considerations: (1) the type of problem studies and (2) a single independent task.

The approaches to decisionmaking are less consistent than those to problem solving. They are developed with a different context in mind. For example, most imply a cyclic aspect or concern about repeatability. In addition, the implementation and consequences absorb more of the total activity. Most decisionmaking approaches evolved out of early problem solving and used complex decision cases as the basic unit of analysis. In other words decisionmaking, especially as viewed in organizations, has a broader effect than problem solving. Perhaps the relationship between the two is as Maier (1973, p. 613) supposed: "Two processes usually are involved in decisionmaking: Problem solving (PS) and choice behavior (C). The first is the discovery of solutions which constitute ways of getting around or removing obstacles; the second is the evaluation process which leads to the selection of a solution from among available alternatives." If this is the case, then the method to 
TABLE 1.- REPRESENTATIVE APPROACHES TO PROBLEM SOLVING

\begin{tabular}{|c|c|c|c|c|c|c|c|}
\hline \multirow[b]{2}{*}{ Stage } & \multicolumn{7}{|c|}{ Approach } \\
\hline & $\begin{array}{l}\text { Wa1las } \\
(1926)\end{array}$ & $\begin{array}{l}\text { Dewey } \\
(1938)\end{array}$ & $\begin{array}{l}\text { Duncker } \\
\text { (1945) }\end{array}$ & $\begin{array}{l}\text { Hutchinson } \\
\text { (1949) }\end{array}$ & $\begin{array}{l}\text { Osborn } \\
\text { (1957) }\end{array}$ & $\begin{array}{l}\text { Polya } \\
(1957)\end{array}$ & $\begin{array}{l}\text { Sackman } \\
(1973)\end{array}$ \\
\hline 1 & $\begin{array}{l}\text { Prepara- } \\
\text { tion }\end{array}$ & $\begin{array}{l}\text { Initiation } \\
\text { of inquiry }\end{array}$ & $\begin{array}{l}\text { Functional } \\
\text { solution }\end{array}$ & Preparation & Orientation & $\begin{array}{l}\text { Understanding } \\
\text { problem }\end{array}$ & Emergence \\
\hline 2 & $\begin{array}{l}\text { Incuba- } \\
\text { tion }\end{array}$ & $\begin{array}{l}\text { Problem } \\
\text { formulation }\end{array}$ & $\begin{array}{l}\text { Reformu- } \\
\text { lating }\end{array}$ & Frustration & Preparation & $\begin{array}{l}\text { Devising a } \\
\text { plan }\end{array}$ & $\begin{array}{l}\text { Competing } \\
\text { approaches }\end{array}$ \\
\hline 3 & $\begin{array}{l}\text { Illumina- } \\
\text { tion }\end{array}$ & $\begin{array}{l}\text { Hypothesis } \\
\text { formulation }\end{array}$ & $\begin{array}{l}\text { Suggestion } \\
\text { from } \\
\text { above }\end{array}$ & Insight & Analysis & $\begin{array}{l}\text { Carrying out } \\
\text { plan }\end{array}$ & $\begin{array}{l}\text { Proposed } \\
\text { plan }\end{array}$ \\
\hline 4 & $\begin{array}{l}\text { Verifica- } \\
\text { tion }\end{array}$ & $\begin{array}{l}\text { Experimental } \\
\text { testing }\end{array}$ & $\begin{array}{l}\text { Suggestion } \\
\text { from } \\
\text { below }\end{array}$ & Verification & Hypothesis & $\begin{array}{l}\text { Checking } \\
\text { (looking } \\
\text { back) }\end{array}$ & $\begin{array}{l}\text { Consensus } \\
\text { and } \\
\text { commitment }\end{array}$ \\
\hline 5 & & $\begin{array}{l}\text { Termination } \\
\text { of inquiry }\end{array}$ & & & Incubation & & Methods \\
\hline 6 & & & & & Synthesis & & $\begin{array}{r}\text { Solution } \\
\text { testing }\end{array}$ \\
\hline 7 & & & & & Verification & & $\begin{array}{l}\text { Consolidation } \\
\text { and } \\
\text { refinement }\end{array}$ \\
\hline 8 & & & & & & & $\begin{array}{l}\text { Communication } \\
\text { of results }\end{array}$ \\
\hline 9 & & & & & & & $\begin{array}{c}\text { Feedback and } \\
\text { evaluation }\end{array}$ \\
\hline
\end{tabular}


TABLE 2.- REPRESENTATIVE APPROACHES TO DECISIONMAKING

\begin{tabular}{|c|c|c|c|c|c|c|}
\hline \multirow{2}{*}{ Stage } & \multicolumn{6}{|c|}{ Approach } \\
\hline & $\begin{array}{l}\text { Abendroth } \\
\quad(1956)\end{array}$ & $\begin{array}{l}\text { Calkins } \\
(1959)\end{array}$ & $\begin{array}{l}\text { Kepner and } \\
\text { Tregoe } \\
\text { (1965) }\end{array}$ & $\begin{array}{c}\text { Drucker } \\
(1967)\end{array}$ & $\begin{array}{l}\text { Weisselberg } \\
\text { and Cowley } \\
(1969)\end{array}$ & $\begin{array}{c}\text { Janis and Mann } \\
\text { (1977) }\end{array}$ \\
\hline 1 & $\begin{array}{l}\text { Analysis of } \\
\text { elements }\end{array}$ & $\begin{array}{l}\text { Identify and } \\
\text { understand }\end{array}$ & $\begin{array}{l}\text { Establish } \\
\text { objectives }\end{array}$ & Type (generic) & Recognition & $\begin{array}{l}\text { Appraising } \\
\text { challenge }\end{array}$ \\
\hline 2 & $\begin{array}{l}\text { Evaluation of } \\
\text { criteria }\end{array}$ & $\begin{array}{l}\text { Define and } \\
\text { clarify goals }\end{array}$ & $\begin{array}{l}\text { Rank } \\
\text { importance }\end{array}$ & Specifications & Definition & $\begin{array}{l}\text { Surveying } \\
\text { alternatives }\end{array}$ \\
\hline 3 & $\begin{array}{l}\text { Appraisal of } \\
\text { information }\end{array}$ & $\begin{array}{l}\text { Pose } \\
\text { alternatives }\end{array}$ & $\begin{array}{l}\text { Alternative } \\
\text { actions }\end{array}$ & $\begin{array}{l}\text { Evaluation of } \\
\text { solutions }\end{array}$ & Analysis & $\begin{array}{l}\text { Weighing } \\
\text { alternatives }\end{array}$ \\
\hline 4 & $\begin{array}{l}\text { Unknown } \\
\text { factors }\end{array}$ & $\begin{array}{l}\text { Analysis of } \\
\text { consequences }\end{array}$ & $\begin{array}{l}\text { Evaluation of } \\
\text { alternatives }\end{array}$ & $\begin{array}{l}\text { Action to } \\
\text { implement }\end{array}$ & Synthesis & Commitment \\
\hline 5 & $\begin{array}{l}\text { Empirical } \\
\text { values }\end{array}$ & Select action & $\begin{array}{r}\text { Tentative } \\
\text { decision }\end{array}$ & Feedback & Choice & $\begin{array}{l}\text { Adhering } \\
\text { (despite } \\
\text { negative } \\
\text { feedback) }\end{array}$ \\
\hline 6 & Weighting & & $\begin{array}{l}\text { Adverse } \\
\text { consequences }\end{array}$ & & Implementation & \\
\hline 7 & $\begin{array}{l}\text { Relative } \\
\text { impact }\end{array}$ & & Implementation & & Follow-up & \\
\hline 8 & $\begin{array}{l}\text { Synthesis to } \\
\text { course of } \\
\text { action }\end{array}$ & & & & & \\
\hline
\end{tabular}


make a decision should be the same as a problem-solving method with the inclusion of a choice mechanism.

In any event, it is an intriguing idea: apply a problem-solving approach to a decision condition or a decision approach to a problem condition and intuitively anticipate the same results. As was pointed out in another paper (Dieterly, 1978) the problem-solving and decisionmaking conditions can be the same if the definition and assumptions presented are accepted. If these statements are valid, which is maintained, then a general process is appropriate to both concepts.

If, then, a similar process is being used to resolve both types of situations, then a single model should be applicable to both. Since there exists no contrary evidence to assume that these methods are incorrect, a general model of the process will be derived from both sets of methods. The model will be called the clarification process model. Therefore, the implication is made that the processes necessary to solve a problem or make a decision are basically the same.

\section{MODEL OF THE CLARIFICATION PROCESS}

In an earlier paper defining the basic model of the decision and problem condition, it was shown that the basic condition model was applicable to both types of study (Dieterly, 1978). The implication was made that the process that was necessary to resolve either case was the same. The clarification model developed here is designed to explain how both types of resolutions are derived. The term decision-problem condition will be used to indicate any condition that establishes a decision or solution requirement. The making of a decision or the solving of a problem will be referred to as a resolution of the decision-problem condition. The clarification process is how a decisionproblem is resolved. The process to be modeled is complex and not well understood. As Blum and Naylor (1969, p. 458) point out: "It is only when we are faced with one of those very 'tough' decisions in which we just cannot seem to make up our minds that we begin to appreciate all the complexities of the process that a person goes through in trying to decide upon an appropriate course of action."

After reviewing these approaches to problem solving and the approaches to decisionmaking, a central core of steps was extracted which represents the necessary components of each concept. The five identified phases are: (1) identify situation, (2) determine options, (3) establish outcomes, (4) evaluate/analyze, and (5) choice and implementation. This phase sequence was selected to portray the necessary pattern required for resolution of a decision-problem condition. Certain functions from problem solving, such as incubation and verification, were not included. Incubation, although certainly a factor, must occur throughout the process. However, since it represents a timing factor, which may be applied at any point, it is not directly stated. Verification is also not included in the process because it occurs after the implementation of the solution. Verification or evaluation is important, but is not considered essential to the task of resolution. 
The categories encountered in the decisionmaking approaches are generally loosely encompassed in the phases selected. As can be seen in figure 1 , the five phases, which may be considered "steps to resolution," are grouped about an information manipulation function. This function represents a type of information process model that occurs within the individual.

A model of the clarification process is shown in figure 1. The mode1 consists of five sequential phases that are centered on a core element. The core element, which is an information manipulation function, interacts with all the phases. Beneath the model is a referenced diagram of the basic condition model. The basic condition model consists of three dimensions: initial state, transition, and end state. As is shown, the initial state is parallel to the phase of identifying the situation. The transition state is parallel to the three phases: determining options, evaluate-analyze, and choice. The end state is parallel to the phase of establishing the outcome. The representation then suggests the relationship between the decision-problem condition model and the clarification process model.
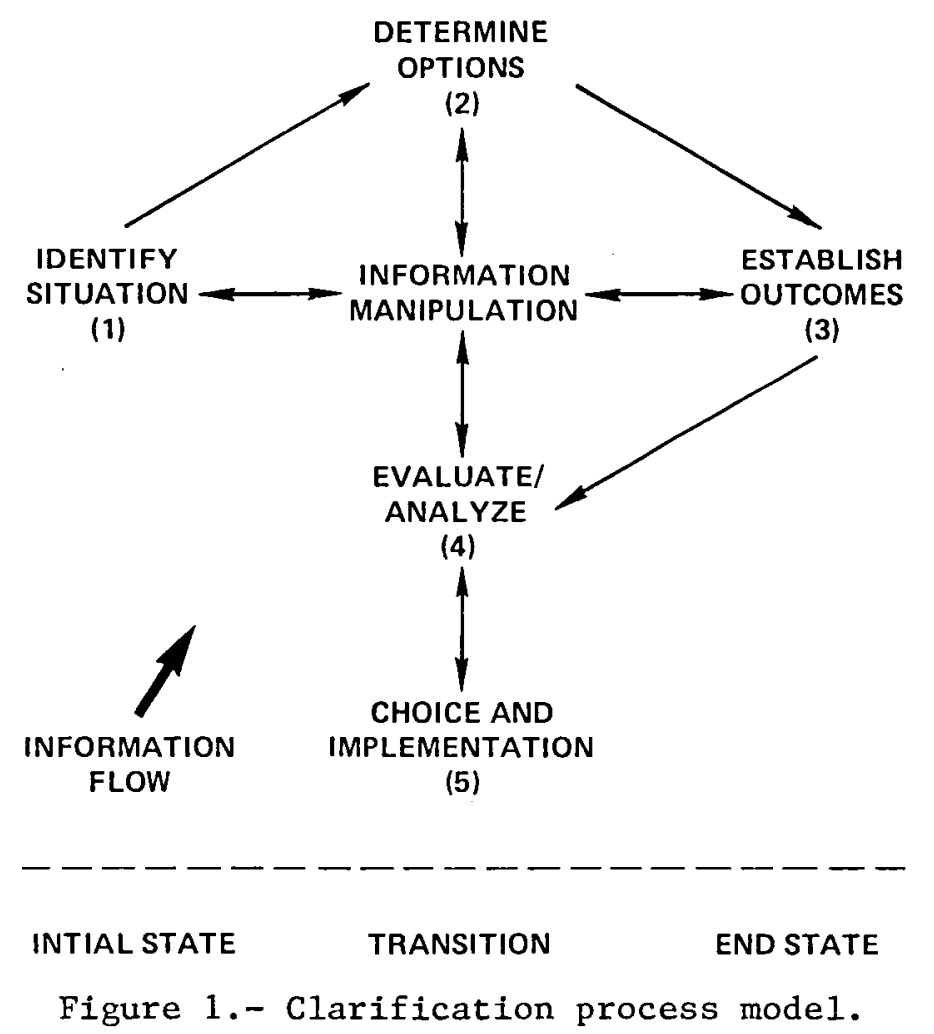

The model is not dependent on the actual choice or implementation of the end state. The elements of expected outcome or expected resolution are inherent in the model. The process will generate the outcome and associated actions for implementation. Once the choice is made and implemented, "success" is anticipated. After implementation, "success" may be determined through verification, evaluation, follow-up, or review. For the purpose of decisionproblem resolution, once the process has been completed, the resolution has 
been completed. However, a further explanation of each phase will better demonstrate this relationship.

\section{Phase I: Identify the Situation}

This phase requires a clarification of the initial state. A clarification of the existing situation, which for some reason is no longer acceptable, is required. The phase establishes a starting point from which to depart; it is the statement of the present state. In this phase, a clear statement of the present condition is established. The manipulation of all information to identify those elements that represent the precise state of the current condition is required. This phase produces a statement that is usually in the form of a qualitative statement. For example: What is the equation for linear decomposition? How do we solve this problem? What we must do is decide how to get across the river. Some of the other phases may emerge in the statement.

Two tasks are accomplished in this phase. First, all available information is processed and integrated into the condition statement. Based on this statement, the second task is to attempt to introduce qualifiable aspects into the condition statement. A second task is to reorder the available information to establish a dimension that may be quantifiably defined. After it is defined the present amount must be established as the base line. For example, if the president of Amalgamated Plastics determined that his production was below quality standards and that as a result the profits on sales for the year were low, an index of quality would be required and applied to establish the initial state. The acquisition of the initial state index may be difficult and time consuming; however, the greater the clarity, the higher the probability of obtaining the final state. The culmination of this phase produces a specification of the initial state.

\section{Phase II: Determine Options}

In this phase the task is to establish a set of options that may attain the final state. The options are those actions or methods that will accomplish the resolution of the decision-process condition. The options identified may be closely associated with the first phase. The clarification of the first phase will place a degree of limit on the options selected. The options are possible methods that when applied will attain the movement from the initial state to the final state. The transitions, as they are identified in the basic model, are bridges from one state to another. The options are usually of the form of a type of action or a technique that would require application or implementation. For example, possible options may be modes of production, that is, assembly line, team assembly, or combinations of both. An option, when initiated, will result in a change of the present pattern either introducing some new process, modifying a current process, or replacing a current process. The underlying implication of the basic model is that only by actually selecting an option will a transition occur out of the initial state. The completion of this phase will be an option set of one or more methods. 


\section{Phase III: Establish Outcomes}

In the third phase, anticipated outcomes are established. The outcomes will be linked to the initial state. Since the initial state and final state are highly related along a set of variables, the quality of clarification attained in the first phase will be reflected in the third phase. The outcomes will also serve to further limit the set of options developed in phase two.

The outcome or final state is the expected state. This state is different from the initial state and has, through some mechanism, been determined as more appropriate than the initial state. If a quantifiable measure has been established for the initial state, then a quantifiable measure may be anticipated in the final state. Frequently, the decision-problem condition is one of an amount or quantity. For example, to improve, to reduce absenteeism, or to raise profits - al1 variations of initia1 states translated to end states. The outcomes are linked to the options in that each outcome is associated with one or more options. The outcomes are directly associated with the initial state established in the first phase. They are related to the transitions determined in the second phase. However, the relationship may be established prior to phase three. If the initial state is described in quantitative terms, then the outcome will be an expected change in this value. All transitions may have been selected to meet this requirement. The phase is completed when one or more outcomes are identified.

\section{Phase IV: Evaluate/Analyze}

This phase requires the application of analysis or evaluation to make a selection of the options established in phase two. A decision-problem condition requires the clarification of the three dimensions of the basic decisionproblem model. After this has occurred, if more than one transition or end state exists, the resolver must select from the set. If the model identified has only one option and one end state, this phase is not required. However, when a decision-problem condition results in multiple options or end states or both, some method of selection must be developed. The method may vary from simple random choice to a complex analytic rule. The type of rule used is called an evaluation rule and its function is to reduce the multiple dimensions. It may require the gathering of additional information and could, in itself, be thought of as a decision-problem condition.

\section{Selection Rule}

The selection rule is a systematic way of considering any multidimensioned variable and allowing for the choice of one over the other. Therefore, in problems of class II-IV the requirement emerges for an evaluation rule (Dieterly, 1978). The rule may be applied and consistent results anticipated. The form of the rule is limited only by the sophistication of the subject and the data available. If, for example, there were two ways to get from New York to San Francisco, plane or train, an evaluation rule may be established to select the option that takes less time or that is the safest or a combination 
of both. The methods for accomplishing this will not be discussed in this report.

Based on the information available, the selection rule is established. The selection rule is the critical aspect of this process and reflects criteria used to weigh possible transitions and end states or, more formally, a mathematical model to be applied. The selection rule may be complex or arbitrary; in any event, it is applied. Frequently, selection rule approximations are applied which reduce the set of transitions but still do not identify the optimum one. Once the selection rule is established, the data are ordered and the rule applied identifying the resolution. The evaluate-analyze phase is completed when one option and one end state are identified.

\section{Phase V: Choice and Implementation}

In the choice phase, the selection of an option is made and applied. This is the last phase. The success of this phase is dependent on what occurred in the preceding phases and during the manipulation function. The expectation of obtaining the end state is set in motion and should be obtained. If the end state is not obtained, the individual will be surprised and the entire process may be started over. If at this point, a11 other phases have been adequately completed, the choice is obvious. An issue may arise as to some external consideration, as to cost of implementation or quality of implementation, but as far as the basic model is concerned, the clarification process is complete and explicit.

The implementation of the choice may require a varying degree of effort, ranging from an individual action (e.g., computing the solution) to a complex set of planned actions involving a total organization (e.g., declaring war). Any evaluation of the choice may require, therefore, considerable effort or only a quick comparison with an answer sheet. The completion of this phase results in a completion of the process.

\section{Total Process}

The clarification process model described presents a series of logical phases that will result in a resolution of a decision-problem condition. The quality of the resolution is dependent on the adequacy of each phase. The apparent linearity of the process is only an effect of the explanation. Actually, it is not expected that the completion of each phase occurs in the sequence shown; it may occur at any point in time. Some information manipulation is occurring on all phases to some degree. The results of each phase have an effect on the other phases.

The phases shown are external to the information manipulation function. This function, discussed next, is a critical aspect of the clarification process. The manipulation of information is the only method that allows for the completion of each phase. The set of phases represent a strategy of decisionproblem condition resolution that is applicable to all classes of conditions. It may also be modified for sepcific decision-problem conditions that are less 
demanding. The clarification phases may be excluded to the point that random guessing results, but this would not be a profitable idea. In general, the phases offer an optimum technique for resolving a decision-problem condition.

\section{INFORMATION MANIPULATION FUNCTION}

This information manipulation (IM) function consists of five subfunctions: (1) attaining, (2) screening, (3) standardizing, (4) classifying, and (5) storing. In addition, a function control mechanism is included. The IM function accommodates all existing information available. Information may be attained either externally or internally. This function is operating constantly throughout the entire clarification process. It is similar to an information processing system and is a crude model of the cognitive capability of the individual. It is through the manipulation of information that the resolution of the decision-problem condition is obtained. In studying decision-problem conditions, it is the information manipulation function that is what is most important, but least understood. The rather simple model shown in figure 2 is provided as a first approximation to demonstrate the potential complexity and

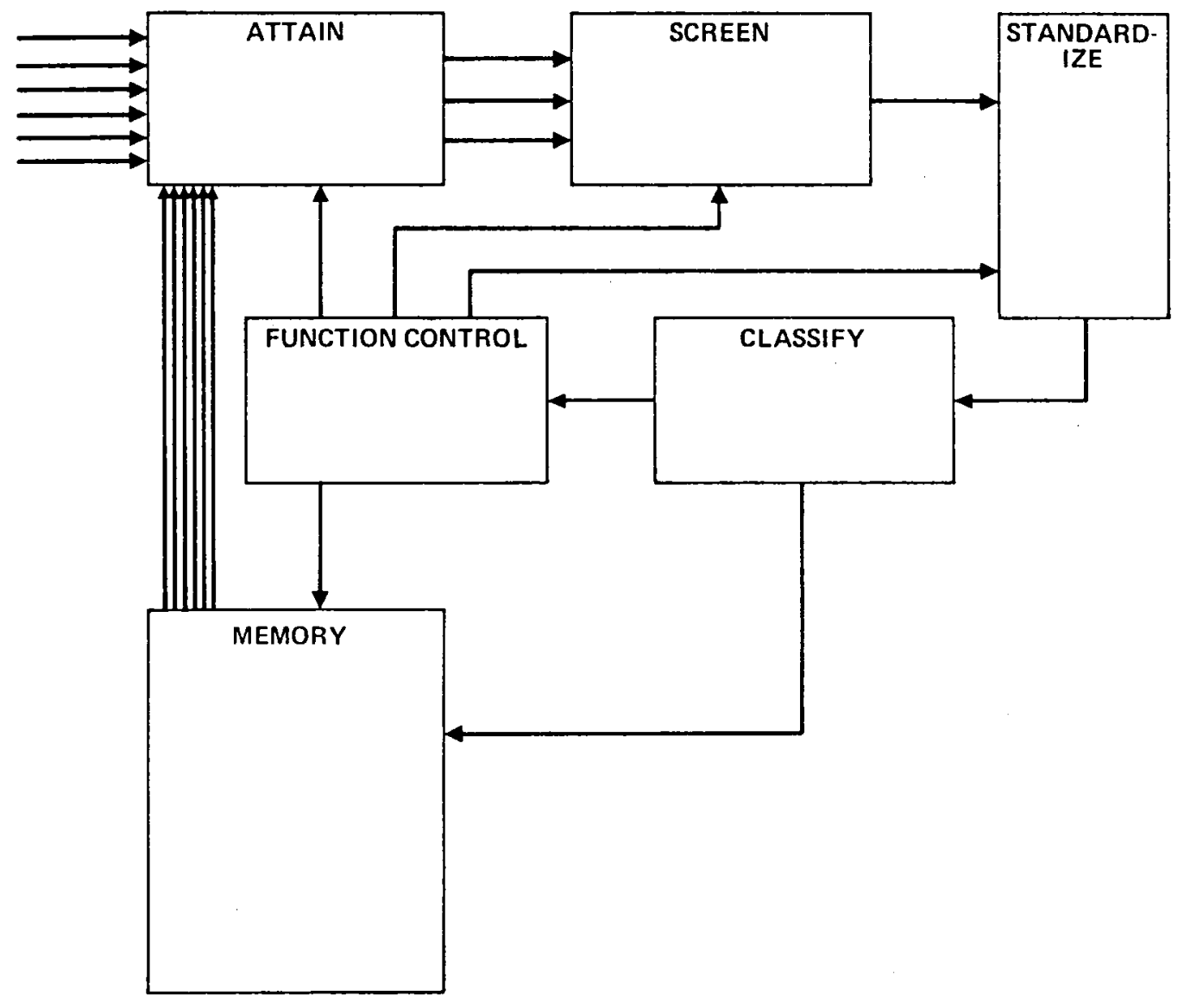

Figure 2.- Information manipulation mode1. 
importance of the individual's cognitive ability in the area of concern. The subfunctions indicated emphasize the manipulation of data into simple structures. The more complex tasks accomplished are beyond the scope of this presentation. A brief discussion of each subfunction will aid in understanding the total function.

The subfunction of attaining information represents the actual sensation and perception of data, both internal and external to the individual. In this subfunction, information that is available will be sensed and processed into the next subfunction of screening.

The screening subfunction takes the product of the first function and screens the information either in terms of a very low-level filter or rather specific context. In the low-level filter operation only extreme information is noted and the individual is not attuned to any specific outcome. In this case only drastic threat information is important so most information is filtered out. In the specific context situation the individual is actively involved in a specific activity and is attuned only to information pertinent to that activity. In this case more apparently pertinate information is allowed to pass into "standardizing," which is the next subfunction.

In standardizing, the information is reduced to appropriate units that are amenable to established units and are of a structure that may be accommodated by the IM system of the individual. A normal standardizing mechanism is developed to handle all information, but if the context calls for it, a different standardizing rule may be used. Once the information is standardized, it is then classified.

In the classification subfunction, the standardized units are ordered and related to an existing classification scheme of the individual. Again, a special classification scheme may be introduced dependent on the context. After classification, a further screen as to whether information should be retained is applied and then the information is placed in storage or memory.

In the memory subfunction, the data are stored along with other available data within the individual. The storage subfunction groups all similar data into sets for possible recall or reordering. The information in storage is integrated and modified, but will always be available for reuse.

The function control mechanism is the actual manager of all activity in the cognitive realm. It is similar to an executive program in a computer: it determines which functions are to be performed and the sequencing, whether more data are needed and the source, how to order current information, and whether a new screening procedure is necessary. The function control represents the more complex aspects of the mind, which are not considered in this presentation.

Because information forms a basic resource that is critical to the clarification process, an attempt has been made to model the manipulation function in terms of information flow. The more complex aspects of resolutions, such as how new solutions are determined, the function of creativity, and the concern with thinking (Duncker, 1945) are not directly addressed. What is 
provided is a model of the clarification process that includes an information manipulation function. Both of these concepts provide a considerable structure to the process necessary to resolve decision-problem conditions. However, the thought process, although alluded to, is not directly addressed.

\section{INFORMATION MANLPULA'TION MODEL,}

The phases of the clarification model are the logical steps to follow in establishing the resolution of a decision-problem condition. The information manipulation model provides a suggested process for accomplishing each phase. The process is information-dependent and avoids a complete explanation of what takes place. It only suggests some of the basic aspects of information manipulation to identify the possible methods to accomplish the phases and at the same time emphasize the importance of information in the study of decisionproblem condition resolution.

In decision-problem conditions there are two sources of information: internal and external sources. The internal source of information is the individual; the external. source is any information the individual can obtain from other sources. The external source may be divided into "given" and "acquired" information. Given information is that provided initially which was used to establish the decision-problem condition. Acquired information is that which is gained through interaction after the clarification process is begun:

'To further understand the information manipulation model, an abstract example is provided. In figures 3-5, the acquisition of information is shown. The source of the information is indicated by a capital letter followed by a numeral to indicate different types of information. Therefore, $G$ indicates given information; $A$ indicates acquired; and $I$ indicates internal information. In stage 1 , the given information is processed. Several basic circumstances appear in this stage. The given set of information consists of six units of information; however, only 5 units are attained. In other words, in the initial subfunction, one unit of information is lost. During the screening subfunction, another unit is excluded; it was considered, but eliminated. In the standardization subfunction, $\mathrm{Gl}$ is too large and is subdivided into three units GlA, GlB, and GlC. In the classification subfunction, the units are grouped into three sets: which parallel the three compliments of the model. In stage 1 the given information is processed. In stage 2 , internal information is processed.

The memory is searched for information that is associated with the given information. When this information is identified (shown in parentheses) it is processed through the subfunctions of attaining, screening, standardizing, classifying, and tunction controlling. What remains is a set of grouped data gained from external and internal sources. The function control evaluates and seeks additional data in the third stage.

In the third stage, additional information is sought from external. sources. Although external data are available, they may not necessarily be 


\section{GIVEN}

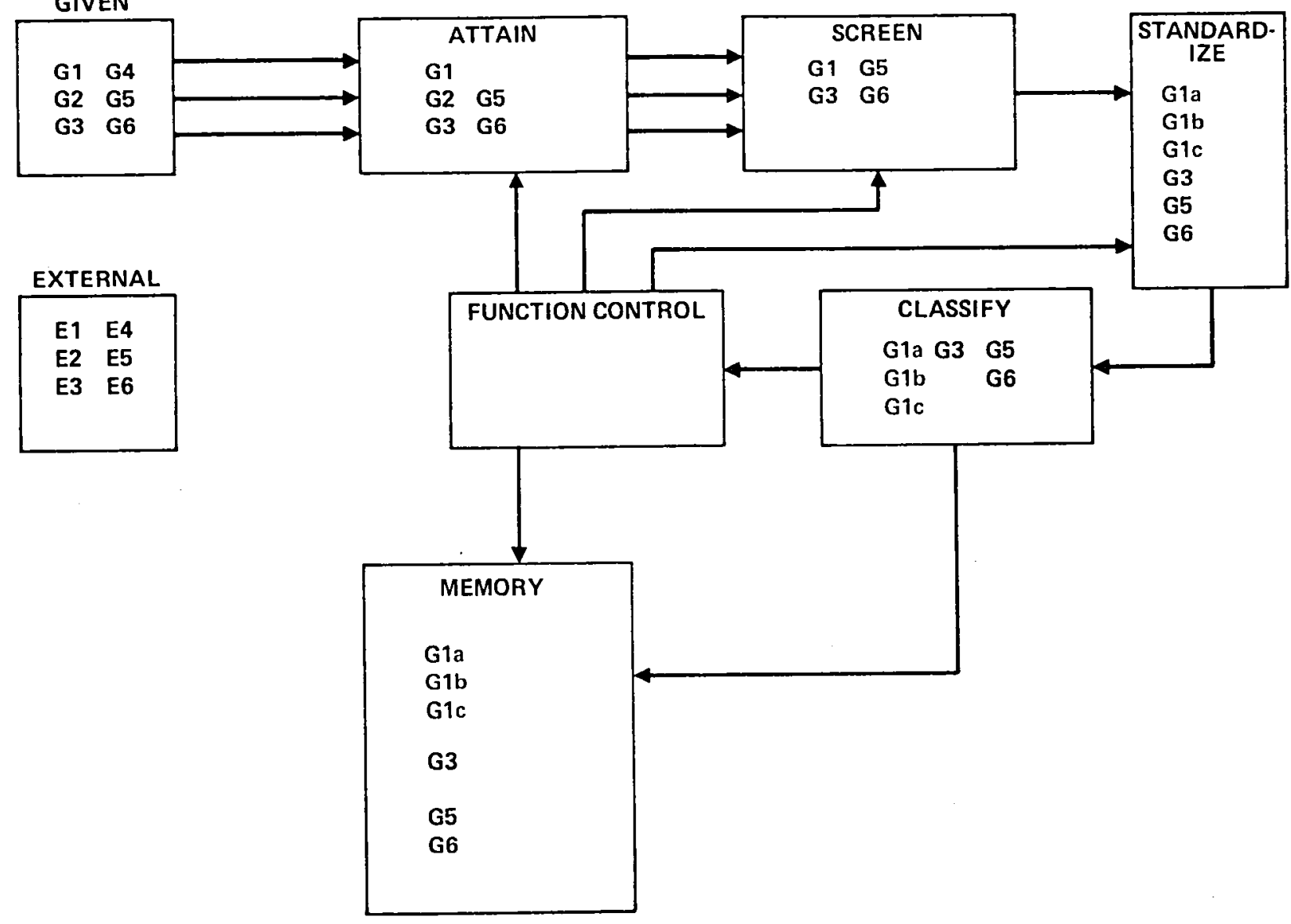

Figure 3.- Information manipulation: stage 1 .

gathered. In the example, only five information units of the six available are processed. What remains at the end of this stage is a set of processed external and internal information categorized in some fashion. From these data, the resolution of the decision-problem will be made.

This basic description of the information manipulation process, may be the critical aspect of the resolution of the decision-problem condition. The availability, form and context of external information is important. In the given information there is a constant amount of information; however, it may not all be processed or it may be processed differently. The acquired information represents a larger, more variable pool of information. The internal information is 1argely unknown. Only by making assumptions about secondary variables, such as age, educational experience, or background, can some estimate of this be established. Information manipulation is the process of interest in the study of decision-problem conditions. 


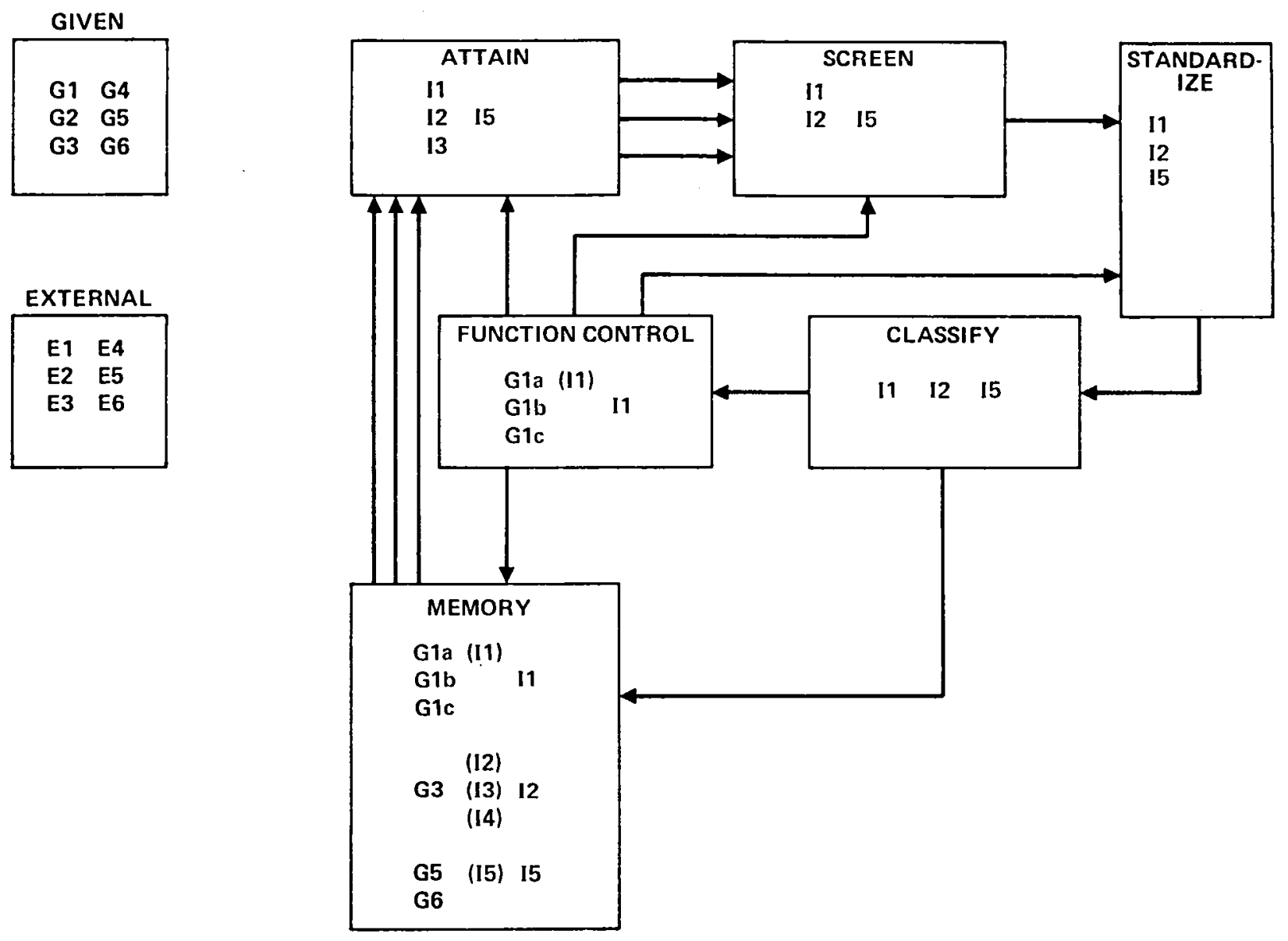

Figure 4.- Information manipulation: stage 2 . 


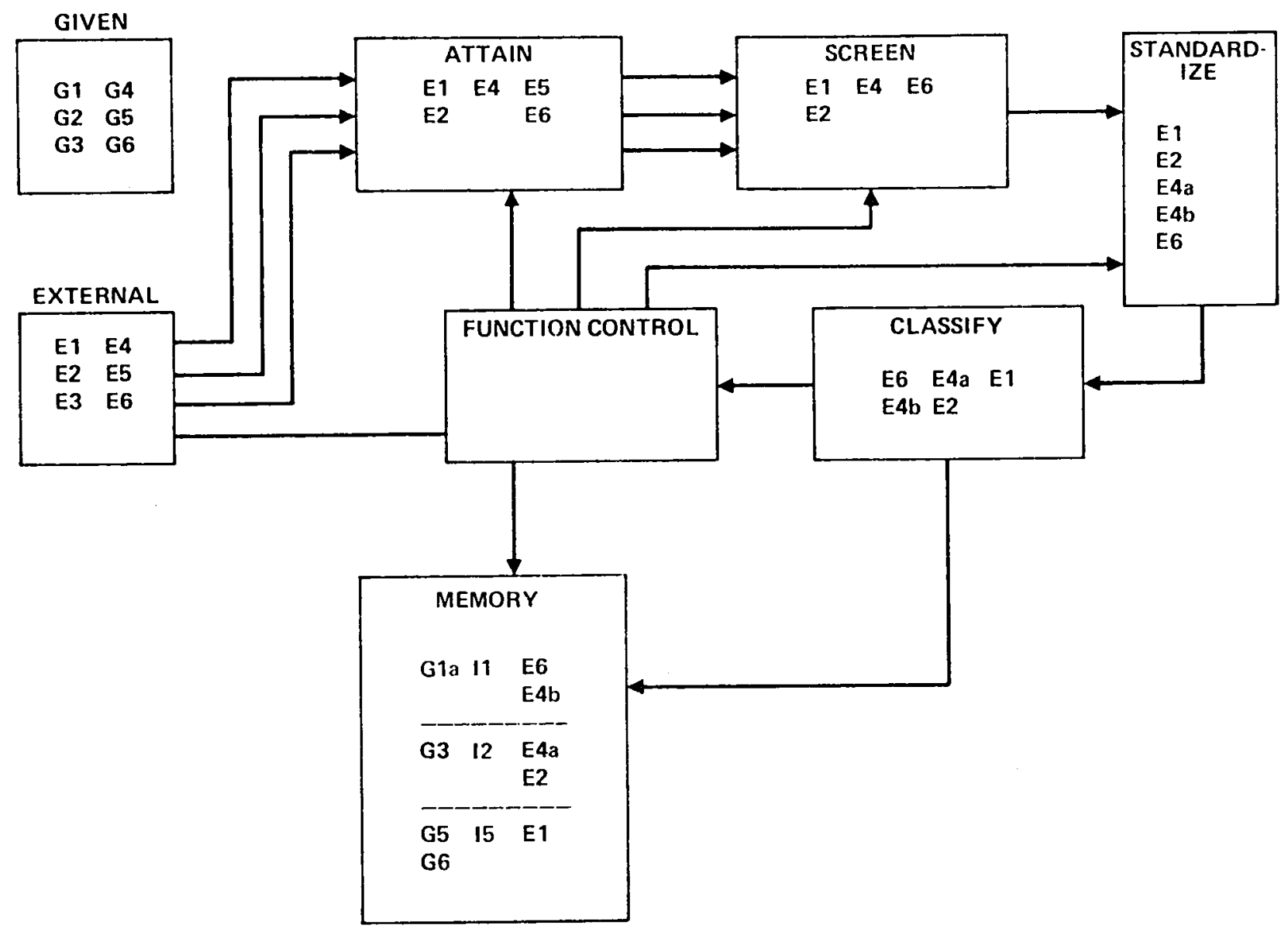

Figure 5.- Information manipulation: stage 3.

INDIVIDUAL CAPABILITY

In decisionmaking and problem-solving research, the mistake of ignoring the resolvers capability is easily made. In decision-problem conditions, where high levels of information are provided or are available, the individual's capability to synthesize is of great importance.

The larger the amount of available information the greater the effect of the individual's capability to screen and classify the information. The capacity of the individual's manipulating process may become a critical issue. Capacity may be threatened in two ways. First, the amount of information per unit of time may exceed the individual's limit, thereby resulting in missed information. Second, the amount necessary to resolve the condition may exceed the total capacity. In the first case, selective-attaining strategies may be adopted. In the second case, new classification schemes may be applied. The ability to standardize into nested units may also be used. This is the ability to generalize the information from multiple units into one cohesive statement. As the amount of external information decreases, the 
subjects own knowledge or information store becomes a dominant factor. That is, the subject has only experience to draw upon to address the task. When the external information is fixes and minimal, when the internal information decreases below a certain level, only crude estimates may be made; therefore, the task may degenerate into that of risk taking or making choices under risky conditions.

When individuals are restrained to use internal information solely to resolve a condition, then their capability is extremely important in reaching an end product. The efficiency of function control aspect of the information manipulation model would take precedence under these circumstances. Once the amount of internal information falls below the function control capability, then the clarification process will begin to fail. The individual will be forced to use heuristic approximations or trial and error responses. In field studies the situation generally occurs due to time or external constraints. That is, the task must be completed by a specified time. The more complex the condition, the greater the effect of variability of individual differences on the results.

\section{INFORMATION AVAILABTLITY}

The entire process assumes complete information availability, a completely valid selection rule, and no external intervention or change through time. Each of these assumptions is normally violated once the clarification process is removed from the control of the laboratory. Information may not be available for three reasons: nonexistent, resource constraint, or unknown. The type of resource constraint is usually time, but it could be manpower, technology, or funding. A valid selection rule is one that is based on appropriate variables. The identification of variables is a task that is highly information-dependent. The quality of the information may, therefore, weaken the selection rule. External intervention may occur in many ways, but it represents an activity that was not considered in the clarification process.

\section{INFORMATION LOCATIONS}

Once a decision-problem condition is established, the information flow into the clarification process must be considered. Essentially, three locations of information are available: (1) immediate surround, (2) individual or members, and (3) external producers. The core of information that was used to establish the situation may be all that is available. This type of decisionproblem condition is the minimum case. At least this much information has to be available. In other words, one source of information must exist and that source is the immediate surround. The amount of information available from the individual is the most variable because it is anchored in the individual's experience. In addition, it is the most difficult to document because there may be no reason for any external indication of what information was used. The information available from external producers may be endless. That is, the supply is so abundant that it must be curtailed in some fashion. 
In studying the clarification process, these locations of information must be considered and evaluated. The method of designing the condition may restrict or constrain the immediate surrounding and externa1 locations of producer information. The systematic selection of subjects may minimize the variability of information within the subjects, but this is the most difficult source of information to control. Many research studies are unconcerned about the information locations and neglect to control this variable. If an improved understanding of the clarification process is sought, the information location problem must be addressed.

Another interesting aspect of the information available from al1 locations is that it may or may not be used. The entire quantity known to exist may be used or only some subset of it. A critical concern may be the amount of information required to resolve conditions with a high rate of success. As the total amount of information increases, the selection subfunction of information manipulation becomes more critical. In addition, the selection may vary or consist of different strategies. For example, as the amount of information increases, a quality level may be applied to pre-screen information. Another difficulty encountered in information-flooded conditions is that a greater number of information subsets are created from which the individual may select. Therefore, in high density information conditions, it is impossible to control the information variable.

RESOLUTION TIME

A situation that indicates a decision-problem condition may emerge rapidly or develop over an extensive time period. The higher the rate of emergence, the more demanding the rate of response. In general, highly volatile, dynamic situations place an inordinate stress on the generation of rapid resolutions. The shorter the response time, the less likely it is that a full clarification process will be applied. Certainly, no time will remain for a further accumulation of information drawn from the situation or the individual. In fact, in these kinds of situations, the subject's approach will revert to some cruder strategy, using a heuristic rule, or even degenerate into a guessing mode. The type of study that demands high resolution rates per unit of time falls into the realm of reaction time or detection signal mode. As the resolution rate exceeds the respondent's capability, the response represents guessing or random actions.

At the opposite extreme, an endless time frame introduces a different problem. That is, the accumulation and processing of increasing amounts of low relevance information. As the amount of information exceeds a mass threshold, it only confounds the process through overload and the introduction of side issues. Therefore, in this condition a screening subfunction takes a disproportionate amount of effort to the point some stop rule must be established to insure a resolution of the decision-problem condition. 


\section{CONCLUSION}

The clarification process model is a model of a general process that occurs in both decisionmaking and problem-solving tasks. The model is highly dependent on information flow. The model addresses the possible constraints of individual differences and experience in achieving success in resolving decision-problem conditions. As indicated, the application of the clarification process model is only necessary for certain classes of the basic decision-problem condition. With less complex decision-problem conditions, certain phases of the model may be omitted. The model may be applied across a wide range of decision-problem conditions.

The mode1 consists of two major components: (1) the five-phase prescriptive sequence based on previous approaches to both concepts and (2) the information manipulation function, which draws on current ideas in the areas of information processing, computer programing, memory and thinking. The two components are linked together to provide a structure that assists in understanding the process of resolving problems and making decisions. Current research in both areas has been directed along different paths. However, it is appropriate to bring it back to the critical issues of resolving problems and making decisions in a competent manner. The process as modeled in this paper attempts to establish the critical link between the two concepts. 


\section{REFERENCES}

Abendroth, W. W.: The Research and Decision Making Process. In Jesse Shera et al. Documentation in Action. New York: Reinhold, 1956.

Blum, M. L.; and Naylor, J. C.: Industrial Psychology: Its Theoretical and Social Foundations. New York: Harper Row, 1968.

Calkins, R. D.: The Decision Process in Administration. Business Horizons, 1959, vol. 2, pp. 19-25.

Dewey, J.: Logic: The Theory of Inquiry. New York: Ho1t Rinehart and Winston, 1938.

Dieterly, D. L.: Problem Solving and Decision Making: An Integration. AFHRL-TR-78- , Air Force Human Resource Laboratory, Brooks AFB, Texas, 1978 (in publication).

Drucker, P. F.: The Effective Executive. New York: Harper \& Row, Publishers, 1967.

Duncker, K.: On Problem Solving. Psychological Monographs 1945, no. 58, p. 5.

Hutchinson, E. D.: How to Think Creatively. New York: Abingdon-Cokesbury, 1949.

Janis, L. J.; and Mann, L.: Decision Making: A Psychological Analysis of Conflict, Choice and Commitment. New York: Free Press, 1975.

Kepner, C. H.; and Tregoe, B. B.: The Rational Manager. New York: McGrawHill Book Co. 1965.

Maier, N. R. F.: Psychology in Industrial Organizations. (4th ed.) Boston: Houghton Mifflin Company, 1973.

Osborn, A.: Ap;lied Imagination. New York: Charles Scribners Sons, 1957.

Polya, G.: How to Solve It. Garden City, New York: Doubleday Anchor, 1957.

Sackman, H.: Preliminary Investigation of Real-World Problem Solving With and Without Computers - Vol. I Summary. Rand Corporation, Santa Monica, California, R-1205/1-NSC, 1973.

Walles, G.: Art of Thought. New York: Harcourt Brace, 1926.

Weisselberg, R. C.; and Cowley, J. C.: The Executive Strategist. New York: McGraw-Hill Book Co. 1969. 


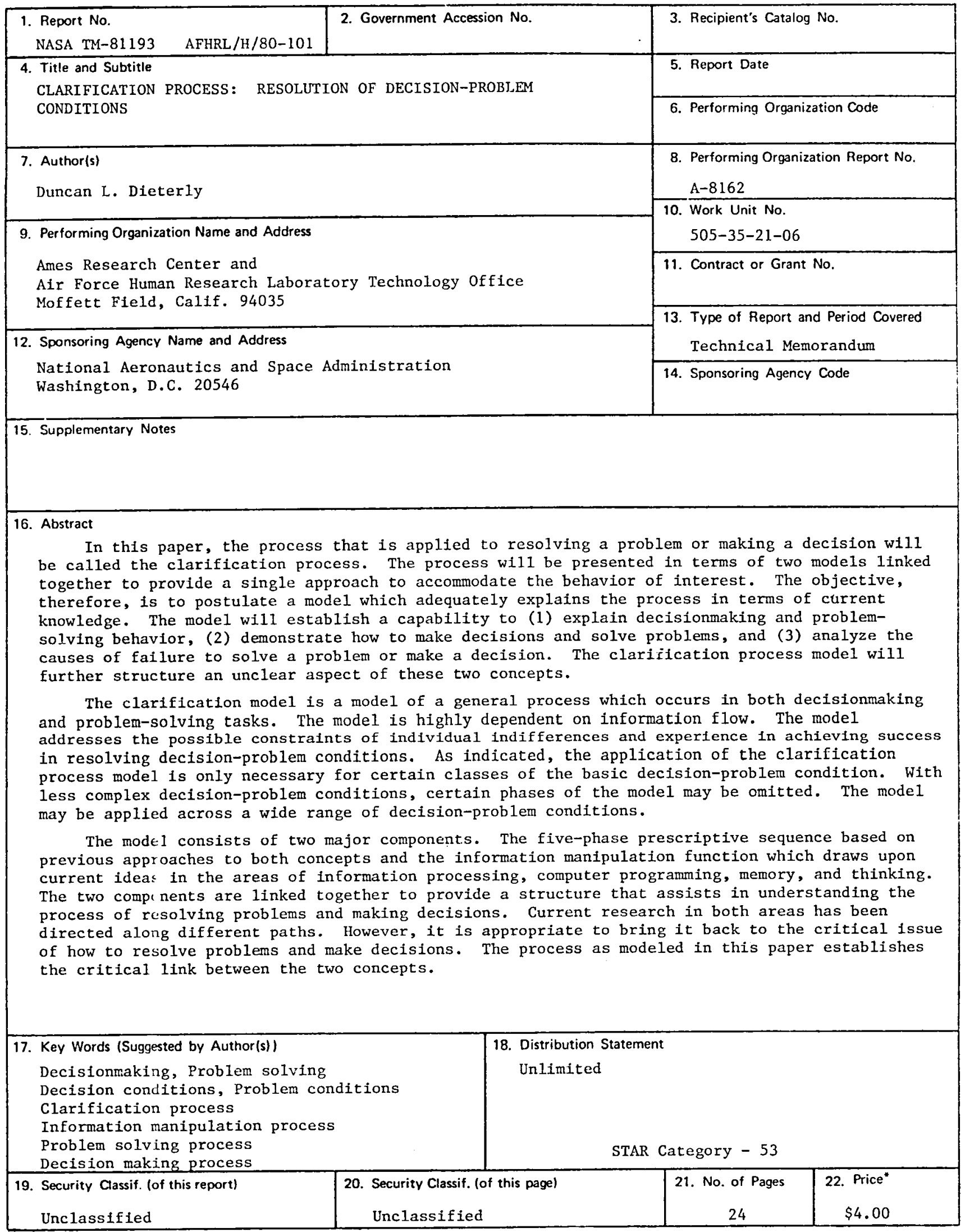

"For sale by the National Technical Information Service, Springfield, Virginia 22161 

